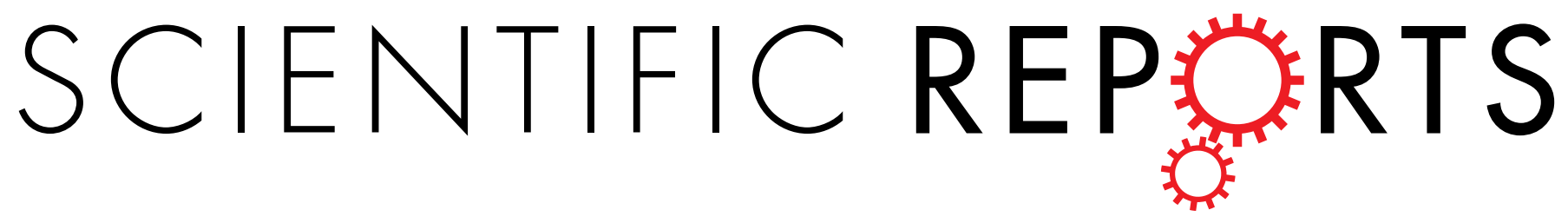

\title{
OPEN Corrigendum: Effects of agricultural intensification on ability of natural enemies to control aphids
}

Zi-Hua Zhao, Cang Hui, Da-Han He \& Bai-Lian Li

Scientific Reports 5:8024; doi: 10.1038/srep08024; published online 26 January 2015; updated on 26 May 2017

This Article contains an error in the order of the Figures. Figures 3 and 4 were published as Figures 4 and 3 respectively. The correct Figures appear below. The Figure legends are correct.
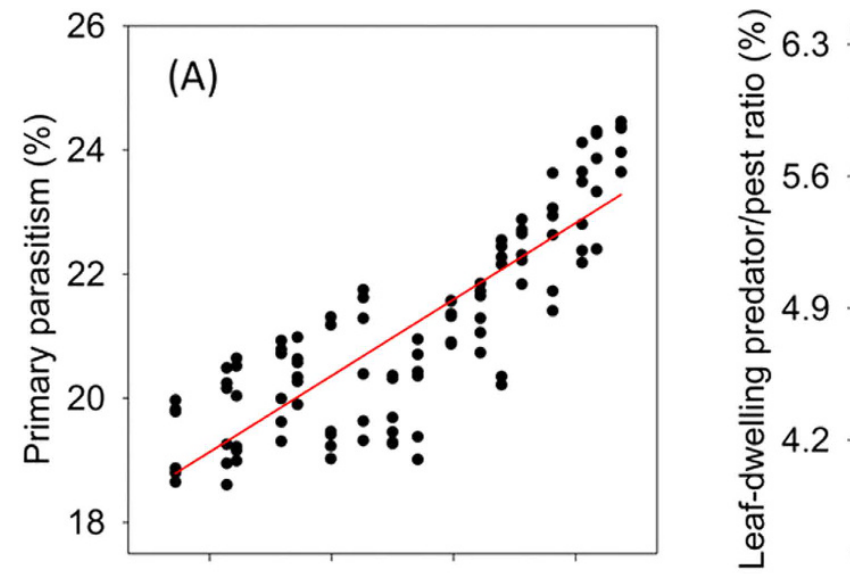

(B)
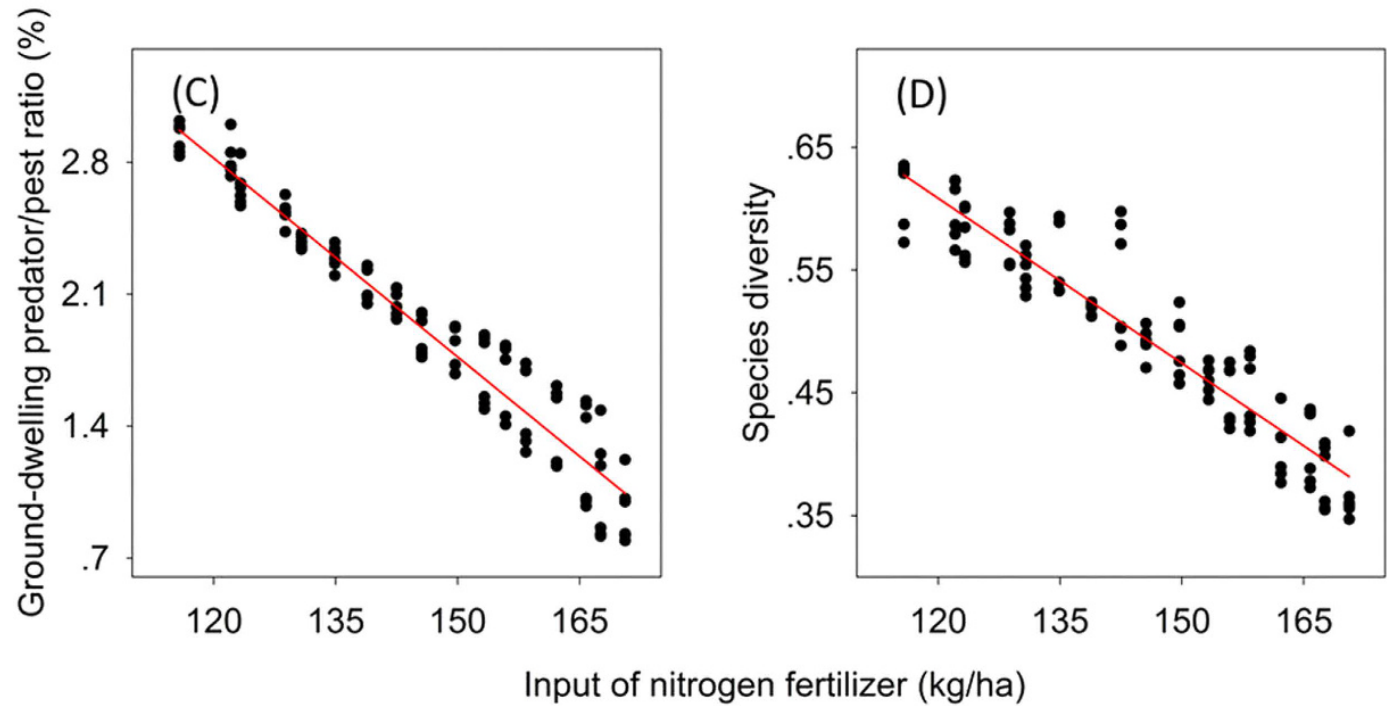

Figure 3. 

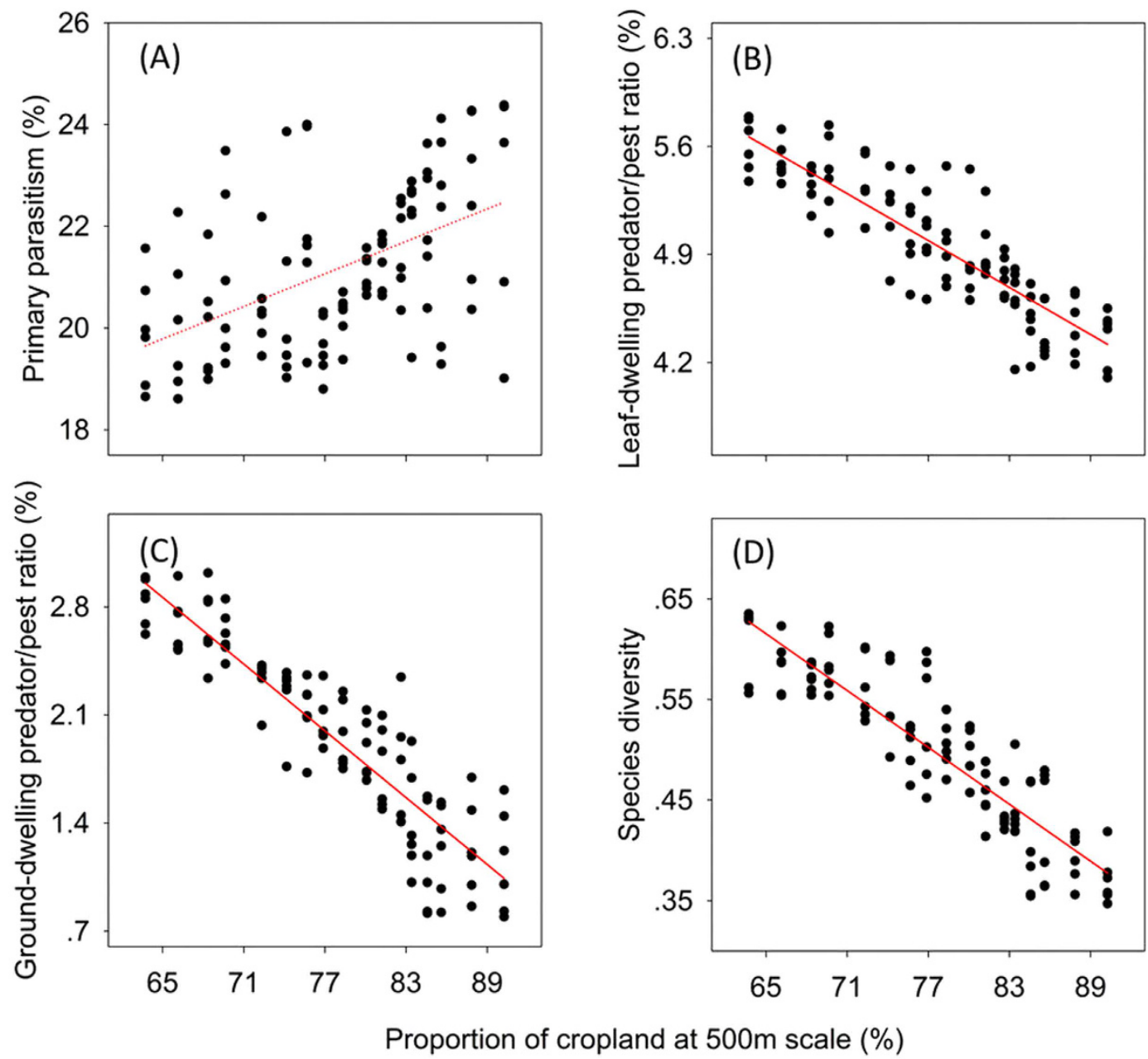

Figure 4.

(c) (i) (2) This work is licensed under a Creative Commons Attribution-NonCommercial-ShareAlike 4.0 (n) ${ }_{\mathrm{BC}}$ SA International License. The images or other third party material in this article are included in the article's Creative Commons license, unless indicated otherwise in the credit line; if the material is not included under the Creative Commons license, users will need to obtain permission from the license holder in order to reproduce the material. To view a copy of this license, visit http://creativecommons.org/licenses/by-nc-sa/4.0/

(c) The Author(s) 2017 